\title{
AS ORGANIZAÇÕES RELIGIOSAS E O PRINCÍPIO DA FRATERNIDADE: VALORES EM VISTA DA MAIOR EFETIVAÇÃO DA PROTEÇÃO INTEGRAL DA CRIANÇA E DO ADOLESCENTE EM TEMPOS E PÓS-PANDEMIA
}

\author{
André Viana Custódio ${ }^{1}$ \\ Jadir Zaro $^{2}$
}

DOI: https://doi.org/10.47306/978-65-88213-03-2.107-121

Sumário: 1 Introdução; 2 Análise dos indicadores sociais da criança e do adolescente; 3 A fraternidade que conduz à cooperação e à participação nas políticas públicas sociais; 4 Organização religiosa e fraterna em vista da maior efetividade das políticas públicas sociais; 5 Conclusão; Referências.

\section{Introdução}

O vínculo existente entre os fatos, a lei e o reconhecimento de valores são de extrema importância para o avanço da humanidade, principalmente nas suas dimensões humanitárias, do bem conviver social e do reconhecimento efetivo da dignidade humana pessoal e coletiva.

Perceber o Estado, a família, a sociedade e neste contexto, as organizações religiosas instituições sociais de valor humanitário é uma forma de lhes atribuir identidade e responsabilidade. As organizações religiosas são instituições que, normalmente, possuem nas suas constituições propósitos e atribuições que reconhecem o valor da natureza humana e tendem a contribuir para que essa característica seja percebida permanentemente.

Ao se analisar os últimos fatos sociais, políticos e econômicos, em que a crise provocada pela pandemia cada vez mais se acentua, questionamentos sobre a situação das crianças e dos adolescentes vêm à tona. Percebe-se que as instituições se sentem fragilizadas no acompanhamento das crianças e dos adolescentes, o isolamento e a falta de articulação social, de recursos se acentuam, ameaçando a proteção integral.

Desejando melhor compreender a dimensão do problema e apresentar alternativas, que

\footnotetext{
1 Doutor em Direito pela Universidade Federal de Santa Catarina com Pós-doutorado na Universidade de Sevilha/Espanha, Coordenador Adjunto e Professor do Programa de Mestrado e Doutorado em Direito da Universidade de Santa Cruz do Sul, Coordenador do Grupo de Estudos em Direitos Humanos de Crianças, Adolescentes e Jovens, Líder do Grupo de Pesquisa Políticas Públicas de Inclusão Social (UNISC). E-mail: andreviana.sc@gmail.com.

${ }^{2}$ Doutorando em Direito (UNISC). Mestre em Direito (UNISC). Graduado: Direito (UCDB), Filosofia (UNIFRA) e Teologia (FAPAS). Diretor da Faculdade Palotina e Integrante do Grupo de Estudos "Direitos Humanos de Crianças, Adolescente e Jovens" (GRUPECA/UNISC).E-mail: jadirzaro@pallottipoa.com.br
} 
se faz a presente abordagem, partindo do seguinte questionamento: analisando as políticas públicas sociais para a proteção integral da criança e do adolescente e o seu declínio, qual é a contribuição das organizações religiosas e a importância do princípio da fraternidade, para a maior efetivação, em tempos e pós-pandemia?

O questionamento se fundamenta nas propostas das políticas públicas sociais desenvolvidas após a Constituição Federal Brasileira de 1988 e o Estatuto da Criança e do Adolescente de 1990, que possibilitaram a mudança de paradigma. Propostas que no contexto atual estão sendo prejudicadas, por fatores políticos, econômicos, culturais e sociais, se agravando ainda mais com a pandemia da Covid-19. Objetiva-se descrever a contribuição que a organização religiosa e o princípio da fraternidade podem dispor para a retomada da proteção integral proposta e o fortalecimento das políticas públicas sociais.

Utilizando-se como método de abordagem dedutivo e método de procedimento monográfico, com técnicas de pesquisa bibliográfica e documental, pretende-se verificar a organizações religiosas e o princípio da fraternidade, sua identidade e valor, demonstrando importância destes para a efetivação dos Direitos da Criança e do Adolescente.

Inicia-se apresentando os indicadores sociais da criança e do adolescente, enfatizando o processo e o retrocesso ocorrido nos últimos tempos. Em seguida, se analisa o princípio da fraternidade, sua importância e contribuição para a efetivação das políticas públicas sociais. Por fim, ressaltando as organizações religiosas e sua identificação com o princípio da fraternidade, se apresentam mecanismos para a retomada e reestruturação das políticas públicas sociais, superando a atual crise e projetando proteção integral da criança e do adolescente com maior efetividade.

Nesta análise conceitual e prática, numa perspectiva histórica e política, se conjuntura maior efetivação da proteção integral da criança e do adolescente, a partir da retomada das políticas públicas sociais, que abordam questões vinculadas à violação de direitos da criança e do adolescente. Políticas públicas sociais que se fundamentam nas normas constitucionais, destacando-se o princípio da fraternidade e nas instituições, aqui destacando a organização religiosa e a sua responsabilidade de contribuir e fortalecer a proteção integral da criança e do adolescente.

\section{Análise dos indicados sociais da criança e do adolescente}

A história tem demonstrado que nem sempre as impressões imediatas dos fatos têm conduzido as verdades e a especificidade dos acontecimentos. Diferentes percepções e análises 
podem surgir dos mesmos registros. Um dos provérbios africanos, dito por um professor da Universidade de Lúria (Nampula), em uma entrevista sobre os projetos brasileiros nos países de Moçambique e Angola, destaca o cuidado necessário com os fatos envoltos em uma questão.

\begin{abstract}
Enquanto ficarmos reféns da história que nos é contada pelos caçadores, que vão à caça e dizem "matei um leão" e não tivemos a possibilidade de ouvir a história dos animais. [...] Nós ficaremos a cantar a música que vem do caçador... O caçador aqui é o grande projeto, os grandes empreendimentos. Então vamos ficar à espera que algum dia os animais possam contar a sua própria história. (informação verbal 139) (GARCIA; KATO; FONTES, 2012, p. 59).
\end{abstract}

Apresentar a situação da criança e do adolescente no contexto contemporâneo, já é um desafio, principalmente ao se ter interesses culturais, econômicos, políticos e sociais adversos, que conduzem a reflexões nem sempre adequadas. Relatar essa mesma situação em pleno período de crise mundial, causado pela pandemia, com reflexos significativos no contexto brasileiro, no convívio social, nas relações intrafamiliares, na presença das crianças e adolescentes em instituições e serviços de atendimento ou locais de lazer, amplia ainda mais esse desafio.

Constatando a impossibilidade de ter dados atualizados e com precisão mais específica referente à efetivação ou não dos direitos da criança e do adolescente, se apresentam as últimas estatísticas formalizadas pelos principais órgãos de controle. Estes podem fundamentar a questão, possibilitando estratégias e meios mais adequados para a efetivação da proteção legal, mas eles são o referencial indicador numa perspectiva que aponta para um número mais significativo de violações, que ainda virão à tona no momento pós-pandemia.

Atenta-se ainda para a percepção dos gráficos e dos números vinculados ao Sistema de Garantias de Direitos da Criança e do Adolescente, vinculados às comunicações e notificações, que não descartam a existência de subnotificações. Contudo, na análise dos direitos da criança e do adolescente e a sua violação, esses dados têm se demonstrado como fonte principal, em vista da elaboração e implementação de políticas públicas sociais, que dão os primeiros passos a partir desta mínima dimensão.

O marco legal, em vista da garantia de direitos humanos de crianças e adolescentes, que fundamenta a proteção integral, demonstra um aperfeiçoamento cada vez mais específico e adequado. Ao recordar a Declaração Universal dos Direitos da Criança, aprovado pela Organização das Nações Unidas (ONU), em 20 de novembro de 1959 e nela perceber que se acentuavam alguns direitos para a criança e o adolescente, se percebe a trajetória percorrida e o que ainda precisa ser adaptado:

Direito a especial proteção para o seu desenvolvimento físico, mental e social. Princípio II 
- A criança gozará de proteção especial e disporá de oportunidade e serviços, a serem estabelecidos em lei por outros meios, de modo que possa desenvolver-se física, mental, moral, espiritual e socialmente de forma saudável e normal, assim como em condições de liberdade e dignidade. Ao promulgar leis com este fim, a consideração fundamental a que se atenderá será o interesse superior da criança. (ONU, 1959).

Enquanto a Organização das Nações Unidas acentuava a necessidade de uma postura específica de proteção para com a criança e o adolescente, o Brasil sustentava uma legislação que permitia violações. O Código de Menores, vigente desde 1927, sustentava a doutrina da situação irregular, sendo indiferente a tratados internacionais (CUSTÓDIO, 2008).

Somente com a aprovação da Constituição Federal Brasileira de 1988 é que se reconhece e normatiza a necessidade de um amparo legal adequado para todas as crianças e adolescentes, possibilitando a proteção integral e um olhar conveniente para um desenvolvimento integral.

Art. 227. É dever da família, da sociedade e do Estado assegurar à criança, ao adolescente e ao jovem, com absoluta prioridade, o direito à vida, à saúde, à alimentação, à educação, ao lazer, à profissionalização, à cultura, à dignidade, ao respeito, à liberdade e à convivência familiar e comunitária, além de colocá-los a salvo de toda forma de negligência, discriminação, exploração, violência, crueldade e opressão. (BRASIL, 1988).

A norma constitucional possibilitou a elaboração do Estatuto da Criança e do Adolescente (ECA), em que se proporcionou a construção do sistema de garantias de direitos estruturando as políticas públicas de atendimento, proteção e justiça.

Pensar em políticas públicas sociais neste contexto, exigia a mudança de paradigmas, a superação das ações de caráter meramente assistencialista, em que a atuação e a tutela do estado apenas se projetavam para atender as crianças e os adolescentes considerados em situação irregular.

Superado esse contexto político e legal, se possibilita a implementação de políticas públicas sociais, ações individuais e coletivas de forma organizada, localizada e estruturada, compartilhando a responsabilidade entre Estado, sociedade e família, em que se incluem as demais organizações.

As políticas públicas sociais que surgiram a partir desse novo marco legal, conduziram a mudança de paradigmas, superando desigualdades e universalizando as propostas e objetivos, conforme propõe e se verifica no Plano Decenal de Direitos Humanos de Crianças e Adolescentes, em seu eixo 1, Diretriz 02.

Universalização do acesso a políticas públicas de qualidade que garantam os direitos humanos de crianças, adolescentes e suas famílias e contemplem a superação das desigualdades, afirmação da diversidade com promoção da equidade e inclusão social. (BRASIL, 2011, p. 1).

As mudanças positivas se fizeram acontecer nas mais diversas áreas e setores sociais, proporcionando alterações significativas e reconhecimentos de direitos e proteções até então 
desconhecidas para as crianças e os adolescentes. Contudo, os atuais números ainda demonstram preocupações.

Em 2018 foram registrados 152.178 tipos de violações. Destes, 72,66\% foram referentes à negligência, seguida por violência psicológica $(48,76 \%)$, violência física $(40,62 \%)$ e violência sexual $(22,40 \%)$. Ressalta-se que, em uma única denúncia pode haver duas ou mais violações. (BRASIL, 2019a).

O quadro de violações de direitos e garantias das crianças e dos adolescentes, que impossibilita o processo contínuo de rompimento de antigas posturas culturais, políticas, econômicas e sociais, conduz ao retrocesso paradigmático e a estagnação. Neste contexto Estado, família e sociedade sentem-se fragilizados e até deixam de atuar positivamente, em vista da proteção integral.

Vejam a situação da infância e adolescência em números:

. 60 milhões de crianças e adolescentes no Brasil (IBGE, 2010)

. 46\% das crianças e adolescentes menores de 14 anos vivem em domicílios com renda per capta até meio salário mínimo (IBGE, 2010)

. $82 \%$ das crianças e adolescentes vivem em áreas urbanas

. 132 mil famílias são chefiadas por crianças e adolescentes entre 10 e 14 anos (IBGE, 2010)

. 1,3 milhões de crianças e adolescentes entre 5 e 15 anos trabalham no Brasil (PNAD) $[\ldots]$

. 76.171 Denúncias registradas pelo Disque Direitos humanos (Disque 100, 2016)

. $15.707(21 \%)$ das denúncias referem-se à violência sexual

. 43.182 denúncias de pornografia infantil na internet (Sfernet, 2016)

.2,487 pontos vulneráveis e exploração sexual de crianças e adolescentes nas rodovias federais (PRF, 2017/2018). (BRASIL, 2019b, p. 22).

A constatação da estagnação do processo de implementação dos direitos da criança e do adolescente, precisa ser avaliada, possibilitando a verificação de retomadas e posturas diferenciadas, em vista de resultados melhores. Alguns fenômenos destacados, como sendo responsáveis pela estagnação ou retrocesso acentuam: a falta de articulação intersetorial dos agentes responsáveis pela organização das políticas públicas socias, problemas na continuidade do processo, mudanças constantes de governo federais, estaduais e municipais, a alteração dos agentes responsáveis pelas políticas públicas sociais e a escassez de recursos financeiros para o setor. (FUNDAÇÃO ABRINQ, 2019).

Novas estratégias para novas mudanças, uma vez tendo acesso aos dados que demonstram o retrocesso, vão se articulando, através das instituições e organizações governamentais e não governamentais. Ressalta-se ainda a importância de se levar em consideração as análises feitas, mas também de se perceber a importância de pensar uma política de estado e não de governo, de se constituir estratégias que enfrentem a origem dessas situações, de forma localizada e participativa. Entre causas e consequências, destaca-se a importância das mudanças da postura social e cultural, em que cidadão e instituições sintam-se identificados e prontos para cooperar. 


\section{A fraternidade que conduz à cooperação e à participação nas políticas públicas sociais}

Interessante o quanto a fraternidade, como bandeira e valor se fez presente nos propósitos e movimentos revolucionários. Por isso, que ao se destacar a fraternidade é importante lembrar do tripé francês: liberdade, igualdade e fraternidade. Ressaltar esse valor, reconhecido como princípio, na história dos direitos humanos é acentuar a sua dimensão como forma de conduzir ao ser humano a sua dimensão social, participativa e coletiva, sem perder aquilo que lhe assegura: a dignidade pessoal.

Apesar do reconhecimento contemporâneo do valor da fraternidade, parece que a história lhes relata uma caminhada paralela, tendo o reconhecimento teórico e legal, sem ser aplicado.

Reconhecer a dimensão principiológica da fraternidade é possibilitar o seu vínculo na densificação dos direitos da criança e do adolescente, em pleno período de distanciamento físico, mas não social, de crise de valores; mas não da importância da contribuição e cooperação. Destacar o princípio da fraternidade e seu vínculo com as políticas públicas sociais, em vista da superação dos desafios atuais, é mais uma quebra de paradigmas. Sendo isso possível, sim; mas ao mesmo tempo desafiador para ser implementado e possibilitar o fortalecimento do poder local, em que mais pessoas e instituições possam estar numa sociedade mais humanizada e humanizadora.

O cenário nacional e internacional tem demonstrado suas dimensões globalizantes e multiculturais, desejando construir meios unificadores e de aproximação. Para isso, tem destacado a construção dos direitos humanos e da dignidade humana, o reconhecimento dos direitos civis, da liberdade, da igualdade e da fraternidade. Acentua-se inclusive que estes são irrenunciáveis, irrevogáveis e intransferíveis.

Desafiador é possibilitar a efetivação de direitos que valorizam a dignidade pessoal, do outro e da coletividade, a indivisibilidade de direitos pessoais e coletivos, numa dimensão em que se assim não for, precisa ser constituído. Pois esses valores estão em todos os seres humanos, independentemente do momento histórico, da cultura, da classe social, da organização social e dos costumes.

E essas características são observadas em todas as sociedades: todo ser humano tem capacidade de pensar, raciocinar, utilizar a linguagem para comunicar-se, de escolher, de julgar, de sonhar, de imaginar projetos de uma vida plena e, principalmente, de estabelecer relações com os seus semelhantes, pautadas em critérios morais. (BARRETTO, 2004, p. 295). 
No contexto atual, ao se reconhecer direitos e valores humanos, a norma legal garante o estabelecido. Desafiador é enfrentar as violações de direito, num contexto que a normalidade dos atos parece conduzir o cidadão a estagnação e aos agentes públicos a indiferença. Ao se acentuar a fraternidade se destaca a integração do princípio e de um valor social, que possibilita a organização e implementação de projetos, de iniciativas sociais de transformação.

A história da humanidade tem favorecido o reconhecimento da liberdade do ser humano, através de direitos, políticas e economias; que também proíbem a sua violação. No Brasil, os órgãos públicos e seus agentes têm por referencial em suas estruturações e iniciativas a igualdade de tratamento e reconhecimento dos cidadãos; devendo pensar e disponibilizar políticas públicas as quais favoreçam igualdade de tratamento e acesso às necessidades básicas dos cidadãos. A fraternidade tem sido desqualificada do seu patamar, não sendo contemplada como fundamento estruturante das políticas públicas sociais.

Percebe-se que a desconsideração da fraternidade tem acontecido na própria alteração deste princípio pela solidariedade. Princípio este também relevante, mas que não demonstra a particularidade da Fraternidade, com seu valor intrínseco e sua abordagem para o combate e o enfrentamento de violações de direitos de crianças e adolescentes.

\footnotetext{
A solidariedade - como muitas vezes foi historicamente realizada - viabiliza que se faça o bem ao outro mesmo mantendo uma posição de força, uma relação 'vertical' que vai do forte ao fraco; a fraternidade, no entanto, pressupõe o relacionamento horizontal, a divisão dos bens e dos poderes, tanto que sempre mais se está elaborando - na teoria e na prática - a ideia de uma 'solidariedade horizontal', que se refere à ajuda mútua entre diferentes sujeitos, sejam estes pertencentes ao âmbito social, seja no nível da paridade institucional. (BAGGIO, 2008, p. 23).
}

$\mathrm{Na}$ composição dos três princípios, liberdade, igualdade e fraternidade, não se tem apenas uma relação, uma possibilidade de abertura parcial ao processo de proteção integral da criança e do adolescente, em tempos de crise, de instabilidade política, econômica e social, mas se constitui uma correlação, uma recíproca projeção aos moldes da responsabilidade compartilhada, favorecendo a humanização social.

\footnotetext{
$\mathrm{Na}$ origem de um comportamento, de uma relação que deve ser instaurada com os outros seres humanos, agindo 'uns em relação aos outros', o que implica também a dimensão de reciprocidade. Nesse sentido, a fraternidade, mais do que um princípio ao lado da liberdade e da igualdade, aparece como aquele que é capaz de tornar esses princípios efetivos. (AQUINO, 2008, p. 137).
}

Entre lutas e revoluções históricas, os princípios da liberdade e da igualdade foram se projetando e moldurando a estrutura de estados e organizações. A liberdade possibilitou o reconhecimento de muitos outros princípios e regras, isso fez com que o sujeito se sentisse muito mais cidadão, com identidade e voz ativa. A igualdade projetou um olhar mais social, na qual se destacasse o desenvolvimento da coletividade em proporções semelhantes, em que o 
acesso e o olhar fossem para o ser humano, independentemente de particularidades.

Ao se dar propriedade à fraternidade se acentua a continuidade desta história humana e social, fortalecendo as políticas públicas de promoção e proteção. A fraternidade amplia o envolvimento social, a responsabilidade, o diálogo, a organização e a tomada de consciência social, aproximando cidadãos e instituições.

Ao ressaltar o princípio da fraternidade se vislumbra a possibilidade de retomada e ampliação das políticas públicas sociais para a infância, em que o cidadão e as instituições tenham uma participação mais efetiva e eficaz.

\begin{abstract}
A redescoberta do princípio da fraternidade apresenta-se como um fator de fundamental importância. Isso porque a experiência e metodologia concernentes à fraternidade são caracterizadas pelos seguintes elementos: (i) compreensão da fraternidade como experiência possível, (ii) o estudo e a interpretação da história, à luz da fraternidade, (iii) a colaboração entre teoria e prática da fraternidade na esfera pública, (iv) a interdisciplinaridade dos estudos e (v) o diálogo entre culturas. (FONSECA, 2019, p. 13-4).
\end{abstract}

Ao analisar as políticas públicas sociais, salienta-se que elas se constituem como a resposta para um problema social. Após a ampliação da compreensão, estudos, análises e projeções, políticas foram pensadas e implementadas, as quais tentassem resgatar uma dignidade infantil afetada. Os números atuais têm demonstrado estagnação ou retrocesso no processo de reconhecimento e valorização do cidadão criança ou adolescente.

Ao se destacar a fraternidade, tem-se por referência iniciativas anteriores, o valor dos demais princípios; mas se amplia a participação cidadã, a sociabilidade do ser humano, demonstrando que ele está para o convívio social e tende a contribuir quando é interpelado e percebe seu espaço. Pois nesta interpelação, lhe é assegurada a liberdade e a condição de ser cidadão, demonstrando a importância da ação fraterna, de cooperação, na percepção do ser humano em si e no outro.

O ser sociável é algo intrínseco ao ser humano, o desejo de conviver e se relacionar com a coletividade faz parte da natureza humana. Na sociabilidade humana é que se constrói a percepção mais específica do outro e da coletividade, em que o ser humano aprende o valor da felicidade, da fraternidade e inclusive da importância da participação social e democrática. (VERONESE, 2015, p. 29).

Apesar da importância legal, a fraternidade possibilita uma antropologia relacional ampliada, uma interdependência pessoal e institucional, que conduz à cooperação e a alteridade, e atitudes relacionais significativas, em que a empatia é o motivador central. Olhar, viver, perceber e valorizar a criança e o adolescente, é possibilitar o reconhecimento de valores até então imperceptíveis. 
Por tempo, a postura assistencialista conduziu o agir coletivo e social frente aos temas relacionados à criança e ao adolescente. Uma vez superada esta postura, espera-se que não se retomem as ações verticais, apesar da crise e do distanciamento físico. A fraternidade se apresenta para demonstrar a importância do ser fraterno, do perceber-se irmão, próximo e responsável, conduzindo a participação e cooperação política e social.

Desta maneira, já é possível se afirmar que uma sociedade se torna fraterna quando participa e integra o texto constitucional com seus valores. Isto faz com que se tenha, concretamente, um fomento a uma sociedade fraterna, como objetiva o preâmbulo da Constituição, já que esta possuiria o status máximo previsto no ordenamento. (VERONESE, 2015, p. 34).

A fraternidade melhor legitima e intensifica o próprio estado democrático. Norma constitucional, liberdade e igualdade, cidadania e dignidade humana, interagem e se fortalecem na fraternidade. Ele é um princípio que ressalta a sociedade participativa e interdependente, no reconhecimento pessoa e do outro, como valores sociais.

A sociedade fraterna frente aos problemas sociais é a que coopera, não por mero assistencialismo, mas por convicções e identificações próprias e coletivas. Políticas públicas pensadas, constituídas e implementadas neste contexto e com tal compreensão fraterna, permitem melhor efetividade e maiores organizações, em vista de propósitos pré-estabelecidos.

\section{Organização religiosa e fraterna em vista da maior efetividade das políticas públicas sociais}

Ao se constituírem as políticas públicas sociais, em vista da proteção integral da criança e do adolescente, num estado democrático de direito, faz-se necessário ter e possibilitar a participação dos cidadãos e organizações vinculadas às finalidades propostas. As instituições, ao identificarem com o proposto, adequadamente e com muita eficácia possibilitam o melhor desenvolvimento local da política pública social e podem contribuir na articulação da participação cidadã.

As organizações religiosas, em sua maioria acompanharam diretamente a história da criança no Brasil. Ao se descrever a invasão colonial, ao relatar a colonização e acentuar os passos intermitentes da migração, da expansão da agricultura e da urbanização, em cada um desses momentos, de alguma forma as organizações religiosas acompanharam e interferiram, coibindo, agindo ou fortalecendo ações.

Apesar disso, o reconhecimento legal e efetivo da organização religiosa, como pessoa jurídica de direito privado, de natureza eclesial, pelas normas brasileiras é algo muito recente. 
Entre os anos de 2002 e 2003, através da Lei 10.825, que definiu as organizações religiosas e os partidos políticos como pessoas jurídicas, e pela Lei 10.406, denominada como Código Civil Brasileiro, se constituiu o reconhecimento legal. "São pessoas jurídicas de direito privado: I as associações; II - as sociedades; III - as fundações; IV - organizações religiosas; V - partidos políticos; VI - as empresas individuais de responsabilidade Limitada-EIRELI" (BRASIL, 2002).

No período que antecede a presente legislação, a organização religiosa atuava consideravelmente, mas precisava se enquadrar nos moldes legais da associação, provocando dificuldades em alguns elementos que lhe são próprios, como identidade, funções, finalidades e objetivos, apresentando uma disparidade constrangedora entre o descrito no estatuto e a atividade desenvolvida.

O reconhecimento legal, estatutário e social da organização religiosa se moldurou e implantou ainda mais, com o Decreto $\mathrm{n}^{\mathrm{o}}$ 7.107, do dia 11 de fevereiro de 2010, fundamentado no Acordo entre a República Federativa do Brasil e a Santa Sé relativo ao Estatuto Jurídico da Igreja Católica no Brasil, possibilitando a sua definitiva conceituação.

Organização Religiosa é uma espécie de pessoa jurídica de direito privado, sem fins lucrativos e de fins não econômicos, criada por lei, de natureza eclesial, integrada por membros de confissão religiosa, detentora de direito próprio ou normas específicas e organizadas nas mais diversas formas de expressão de fé e de culto. (EAJUD, 2015, p. 15).

O Decreto oficializou e legalizou a liberdade de organização, estruturação interna e atuação das organizações religiosas, tais como igrejas, sinagogas, mesquitas, centros espíritas lhes foi permitida, inclusive em âmbito internacional, desde que respeitada a legislação brasileira e não firam princípios constitucionais.

Através do reconhecimento legal feito pelo estado brasileiro, se pode melhor detalhar e definir a atuação das organizações religiosas na promoção e proteção da dignidade humana, em todas as suas dimensões, lhes atribuindo inclusive função identificadora institucional, como sentido existencial e atuação pública social.

Diversas organizações religiosas têm significativa atuação nas áreas da saúde assistência social e educacional, destinadas principalmente ao atendimento de idosos, crianças e jovens. As motivações para isto, se encontram nas finalidades institucionais e principalmente identidade institucional. Nesta identificação interna, tem-se o reconhecimento da fraternidade como princípio fundante e elemento relevante para o ser da instituição e seus membros.

Portanto, estar vinculado a uma organização religiosa em que atua oferecendo a proteção integral da criança e do adolescente, é ter ciência da importância da fraternidade, é 
agir com empatia e alteridade em vista dos Direitos da Criança e do Adolescente. Mas além disso, é possibilitar que cada vez mais, pessoas, instituições e a coletividade, tenham em suas ações esses propósitos e princípios, possibilitando uma ação mais efetiva.

A vida, cada vez mais complexa, faz com que seja necessário a conjugação de esforços
de vários indivíduos para a consecução de objetivos comuns. Isso porque o homem
não encontra em si forças e recursos suficientes para desenvolver sozinho todas as
atividades que almeja e assim suprir todas as suas necessidades e as da comunidade
em que se insere. Esses esforços são realizados diretamente pelo próprio homem
enquanto capaz juridicamente de adquirir direitos, de exercê-los e deles dispor
diretamente ou por meio de agrupamentos de pessoas ou de uma massa de bens.
(PAES, 2006, p. 55).

Perceba-se, contudo, que esta atuação das organizações religiosas não deve ser motivada por conveniência ou tratado, mas pela consciência e adesão da natureza institucional, em que fraternidade, cooperação, dignidade humana e sua promoção são referências existenciais.

As atuações das organizações religiosas, diferentemente de outras posturas institucionais ou pessoais, principalmente, em vista da proteção integral da criança e do adolescente, são definidas como ações apostólicas, missionárias, de evangelização e promoção humana, mas elas têm por fundamento os valores identificadores internos. Contudo, podem conduzir e orientar uma coletividade muito mais ampla, propondo mudanças sociais e posturas públicas; pois elas fazem parte do ser humano.

Reconhecer a dignidade humana, cooperar, ser fraterno, perceber a dignidade humana em si e no outro, são valores que se transmite e aprende. A organização religiosa tem, portanto, ao destacar esses valores, a capacidade de vivenciá-los como identidade e missão, provocando transformações públicas e sociais, e fazendo dos seus propósitos institucionais, um benefício social.

Os participantes de uma organização religiosa, normalmente são conhecidos como membros, unidos por um vínculo fraterno e permanente. Nas suas participações públicas e sociais, a unidade e fraternidade demonstram-se com um diferencial positivo, proporcionando possíveis bons resultados, nas responsabilidades assumidas.

Ao se acentuar a necessidade de retomada e fortalecimento das políticas públicas sociais vinculadas ao sistema de garantia de direitos da criança e do adolescente, em todas as suas fases e dimensões, conforme os princípios estruturantes e concretizantes, como proteção integral, universalização, interesse superior da criança, caráter jurídico-garantista, descentralização político-administrativa, participação popular, desjurisdicionalização, humanização, despolicialização (descriminalização), ênfase nas políticas sociais básicas (CUSTÓDIO, 2008, p. 32), a fraternidade e as organizações religiosas podem contribuir para melhor organização e 
resultados.

Acompanhando a responsabilidade compartilhada entre Estado, família e sociedade (BRASIL, 1988, art. 227), e estando vinculadas a elas, as organizações religiosas tendem a contribuir e fortalecer o sistema de garantia de direitos da criança e do adolescente. As organizações religiosas podem fazer de seus propósitos uma possibilidade, mas além disso, demonstrar que a sua identidade, em que participação e responsabilidade se fortalecem na fraternidade, tendem a contribuir para todo ambiente social e suas políticas; para que a prioridade absoluta da criança e do adolescente se concretize a partir de uma atuação fraterna de toda sociedade.

A organização religiosa, instituída a partir de um referencial de ação, em que a dignidade humana é valorizada, em que a criança e o adolescente são vistas como modelo, com prioridade absoluta, pode até errar em algum momento; mas tem na sua identidade a postura institucional de promoção e defesa das crianças e dos adolescentes. Como se descreve elementos vinculantes institucionais e missionários de uma organização religiosa.

Ele abençoa as crianças trazidas até ele e ensina que o reino de Deus pertence a elas. Ele faz das crianças modelos para se entrar no reino de Deus. Ele também faz delas modelos de grandeza no reino de Deus. Ele convida seus discípulos a receberem as criancinhas como ele faz e transforma o serviço às crianças em sinal de grandeza no reino de Deus. (GUNDRY-VOLF, 2013, p. 3).

Ao se perceber que o princípio da fraternidade proporciona fundamentos institucionais e vínculos sociais, favorecendo a dignidade humana, uma vez que o ser humano percebe o valor preponderante deste princípio, tem-se a possibilidade de olhar para a criança e o adolescente, não de forma lamentável, mas com responsabilidade e comprometimento, sob a ótica de nossas alternativas e possíveis realizações.

As mudanças de paradigmas, semelhantes as demais mudanças sociais, tendem a encontrar limitadores, muito similares aos que conduziram à estagnação e ao retrocesso que hoje se presencia nas políticas públicas sociais vinculadas aos sistemas de garantias de direitos das crianças e dos adolescentes. Perceber no princípio da fraternidade e vincular-se a postura fraterna vivenciada por instituições religiosas, acolhendo, protegendo e favorecendo o desenvolvimento integral da criança e do adolescente é uma alternativa com potencial significativo para a superação da atual crise provocada pela pandemia e um caminho para a mudança do agir social, em que o ser humano volte a perceber um identificador pessoal e encontre no outro a promoção da dignidade da pessoa humana.

A participação popular, a organização de movimentos, a preocupação com o outro, com o bem da coletividade, do bem público, a apresentação de associações e iniciativas em 
tempo de crise, normalmente se acentuam. Mas se a promoção de direitos deve ser perpetuada, esta precisa estar acompanhada de valores permanentes, que transformam posturas sociais, culturais, econômicas e políticas, não se fragmentando em tempos de bem-estar social.

A convicção de que sozinho pouco se consegue, já faz parte da compreensão social, tanto que motivou o surgimento de tantas pessoas jurídicas. O desafio está em perceber os valores institucionais, como a fraternidade, e fortalecer a transformação social, o rompimento com paradigmas que violam direitos e garantias estabelecidos. Se a fraternidade já conduziu a ação de tantas organizações religiosas para a realização de suas finalidades, com sucesso e de forma contínua, uma vez percebido como princípio social, ela tende a contribuir na promoção do Direito da Criança e do Adolescente, aqui destacados e prejudicados por crises passadas e presentes.

\section{Conclusão}

O descompasso entre as determinações legais que contemplam a proteção integral da criança e do adolescente, para com os acontecimentos e a proposição de políticas públicas sociais, parece seguir um modo dialético de ser. Entre retrocessos e avanços, vão surtindo alternativas e resultados díspares.

Parece que os diversos mecanismos e interesses favoráveis interpelam um constante vigiar social, conduzindo aos profissionais das mais diversas áreas a estarem atentos a este constante vir a ser. Pode-se dizer que ainda não se vive numa sociedade que está convicta de que crianças e adolescentes precisam de uma proteção integral e que estão num processo peculiar de desenvolvimento.

O desejo de encontrar novas alternativas para a maior efetivação dos direitos da criança e do adolescente, estando atento ao passado, aos desafios presentes e as inseguranças futuras, justificam a presente abordagem e possibilitarão outros debates. Acredita-se que o importante, todas as vezes que se percebe a violação de direitos, é não manter a indiferença.

Propondo alternativas para maior efetivação dos Direitos da Criança e do adolescente, apresenta-se o princípio da fraternidade, a sua relevância histórica e no contexto atual. Ao se perceber que a fraternidade poderia ter auxiliado na estruturação de uma sociedade humanitária, em que seres humanos não se sentissem comprometidos com o outro apenas por encontrá-lo numa situação degradante, mas pelo vínculo existencial.

Nesta mesma perspectiva, considera-se importante acentuar a responsabilidade compartilhada do Estado, da sociedade e da família na proteção integral da criança e do 
adolescente, que acentua o trabalho individual e em conjunto. As organizações religiosas, conforme seus valores e fundamentações tendem a fortalecer a unidade e cooperação, conduzindo a efetivação do valor protegido, uma vez que faz da responsabilidade da coletividade a sua missão.

Por fim, como é importante perceber que a atual crise não precisa perpetuar, que desafios sempre existiram e continuarão existindo. Mas que proteção integral das crianças e dos adolescentes não é alternativa, é missão, responsabilidade compartilhada e identificador de uma sociedade fraterna, humana e humanizada.

\section{REFERÊNCIAS}

AQUINO, M. Fraternidade e direitos humanos. In: Baggio, A. M. (org.). O Princípio Esquecido. São Paulo: Editora Cidade Nova, 2008.

BAGGIO, Antonio Maria. O princípio esquecido. São Paulo: Cidade Nova. 2008.

BARRETO, Vicente de Paulo. Multiculturalismo e direitos humanos: um conflito insolúvel? In: BALDI, César Augusto (Org.). Direitos humanos na sociedade cosmopolita. Rio de Janeiro: Renovar, 2004.

BRASIL. Acordo entre o Governo da República Federativa do Brasil e a Santa Sé. Decreto $\mathrm{n}^{\circ}$ 7.107, de 11 de fevereiro de 2010. Disponível em: $<$ http://www.planalto.gov.br/ccivil_03/_ato2007-2010/2010/decreto/d7107.htm>. Acesso em: 30 jun. 2020.

BRASIL. Código Civil Brasileiro. Lei n ${ }^{\circ} 10.406$, de 10 de janeiro de 2002. Disponível em: $<$ http://www.planalto.gov.br/ccivil_03/leis/2002/110406.htm>. Acesso em: 30 jun. 2020.

BRASIL. Constituição da república federativa do Brasil de 1988. De 05 de outubro de 1988. Disponível em: <http://www.planalto.gov.br/ccivil_03/constituicao/constituicao.htm>. Acesso em: 30 jun. de 2020.

BRASIL. Crianças e adolescentes: balanço do Disque 100 aponta mais de 76 mil vítimas. 2019a. Disponível em: <https://www.gov.br/mdh/pt-br/assuntos/noticias/2019/junho/criancase-adolescentes-balanco-do-disque-100-aponta-mais-de-76-mil-vitimas $>$. Acesso em 30 jun. 2020 .

BRASIL. Estatuto da Criança e do Adolescente. Lei n ${ }^{\circ}$ 8.069, de 13 de julho de 1990. Disponível em: <http://www.planalto.gov.br/ccivil_03/LEIS/L8069.htm>. Acesso em: 30 jun. 2020.

BRASIL. Mapeamento dos Pontos Vulneráveis à Exploração Sexual de Crianças e Adolescentes nas Rodovias Federais Brasileiras. 2019b. Disponível em: $<$ https://www.chegadetrabalhoinfantil.org.br/wp-content/uploads/2019/04/MapearCartilha.pdf $>$. Acesso em $>30$ jun. 2020. 
BRASIL. CONANDA. Plano Decenal de Direitos Humanos de Crianças e Adolescentes. 2011. Disponível em: $<$ https://www.gov.br/mdh/pt-br/acesso-a-informacao/participacaosocial/conselho-nacional-dos-direitos-da-crianca-e-do-adolescente-conanda/documentos $>$. Acesso em: 30 jun. 2020.

CUSTÓDIO, André. Teoria da proteção integral: pressupostos para a compreensão do direito da criança e do adolescente. Revista do Direito, Santa Cruz do Sul, n. 29, p. 22-43, jan./jun. 2008.

DINIZ, Maria Tereza. Organização Religiosa: nova ordem institucional. Brasília: EAJUD, 2015.

FONSECA, Reinaldo Soares da. Apresentação. In: VERNONESE, Josiane Rose Petry; FONSECA, Reynaldo Soares da. Literatura, direito e fraternidade. Florianópolis: EMais, 2019.

FUNDAÇÃO ABRINQ. Cenário da infância e adolescência no Brasil 2019. 2020

Disponível em: < https://www.fadc.org.br/noticias/cenario-da-infancia-e-adolescencia-20201 ed $>$. Acesso em: 30 jun. 2020.

GARCIA; Ana Saggioro; KATO, Karina; FONTES, Camila. A história contada pela caça ou pelo caçador? Perspectivas sobre o Brasil em Angola e Moçambique. Disponível em: $<$ http://www.pacs.org.br/files/2013/03/Relatorio-Africa.pdf>. Acesso em: 30 jun. 2020.

GUNDRY-VOLF, Judith M. O menor e o maior: crianças no Novo Testamento. 2013. Disponível em: <http://www.redemaosdadas.org/wpcontent/uploads/2013/11/o_menor_e_o_maior-marcia_bunge.pdf $>$. Acesso em: 30 jun. 2020.

ONU. Declaração Universal dos Direitos das Crianças. 1959. Disponível em: $<$ http://www.dhnet.org.br/direitos/sip/onu/c_a/lex41.htm>. Acesso em 30 jun. 2020.

PAES, J. E. S. Fundações, associações e entidades de interesse social: aspectos jurídicos, administrativos, contábeis, trabalhistas e tributários. 6. ed. rev. atual. e ampl. Brasília: Brasília Jurídica, 2006.

VERONESE, Eduardo Rafael Petry. Um conceito de fraternidade para o direito. Rio de Janeiro: Lumen Juris, 2015. 